\title{
La Moderna Inteligencia
}

\author{
Brasileña
}

En el año de 1871, el Emperador brasileño D. Pedro II llegaba a Portugal, cumpliendo un programa de visitas al Viejo Mundo y al Oriente Próximo. En su rápido pasaje por Lisboa, camino a España, D. Pedro II insistió en ser llamado Pedro de Alcántara, pues el Emperador, decía el, quedaba en el Brasil. Su viaje era de carácter particular, y asi deseaba que todos lo considerasen. Nueve meses después, D. Pedro II retorna a Portugal, ahora en tránsito un poco más largo: doce días de permanencia en la tierra de su padre, antes de regresar al Brasil.

Estos doce días, pasados en Lisboa, Braga, Porto y Coimbra, fueron suficientes para que dos escritores, Eca de Queiroz y Ramalho Ortigao, responsables de una revista llamada "Far pas", se aprovechasen de la visita imperial para iniciar campaña un tanto incisiva contra D. Pedro II, el motivo de todo: la modestia y las maneras democráticas del Emperador, sus inclinaciones por la convivencia con los intelectuales, su interés, científico, y hasta la propia maleta que el real visitante siempre traía consigo, era motivo de crítica mordaz y de la ironía de los terribles panfletistas: lanzaban ellos sus "farpas" im. piadosas contra la figura serena y respetable del Soberano brasileño.

Es claro que los dos irreverentes y atrevidos escritores nada tenían contra el pacífico Pedro II. Pero, el Emperador 
del Brasil era lo que hoy se llama noticia -y noticia importante- capaz de colocar en el objetivo del interés público las ediciones de la revista y la figura de sus directores, tan hábiles en el manejo de la pluma espirituosa. Y la "farpas" fueron un éxito en Portugal, aunque en el Brasil éstas viniesen a provo. car agitación y protestas por la incontinencia del lenguaje en relación al Brasil y a su Emperador.

Pero el asunto trae otro asunto y los dos escritores, dejando de lado a D. Pedro II, encaminaron su crítica a ciertos tipos y aspectos del Brasil. Ramalho Ortigao, por ejemplo, herido en su sensibilidad de portugués, no permitía siquiera un pequeño desliz en la pronunciación y en la sintaxis del idioma de Camoes, lamentaba las adaptaciones lingüísticas en el Brasil, en torno de un portugués más suave, tropicalmente endulzado por la naturaleza brasileña y por los contactos con el indio y el negro. Es preciso poner término a ese "desborde de brasileño sobre el portugués de Camoes", reclamaba él en un artículo de "Farpas", mientras su compañero Eca de Queiroz hacía restricciones a ese lenguaje raro que "parece portugués con azúcar".

Eca de Queiroz rectifić, nás tarde, algunos de sus puntos de vista injustos sobre el Brasil y sus instituciones. La convivencia con algunosintelectuales brasileños, amigos que le hacían compañía en las jveladaseliterarias de París, hizo al novelista portugués modificar ciertos conceptos que las distorsiones de una campaña periodística llevaron a la crítica improcedente y a la caricatura exagerada.

Pero, Eca de Queiroz, continuó emitiendo sus opiniones sobre la realidad brasileña. Hay por ejemplo, en un libro suyo, "Ultimas páginas", una carta al brasileño Eduardo Prado, hombre de inteligencia y amigo intimo de Eca, en la cual el autor, bajo la piel de Fradique Mendes, pretende resumir la verdad sobre el Brasil de 1888: "Los brasileños", afirma, "desde el Emperador al trabajador andan destruyendo, y por lo tanto arruinando al Brasil". ¿Y por qué esto? Pues porque, responde Eca, los brasileños, tienen "todo para crear en su suelo espléndido", y "fundar la civilización que deseasen pero prefirieron la imitación europea".

Fradique Mendes, mejor Eca de Queiroz, afirmaba al amigo Eduardo Prado que deseaba el nacimiento, en el Brasil, "con lozana y pura originalidad", de "ideas, sentimientos, costumbres", de "una literatura, un arte, una ética, una filosofía, toda 
una civilización armónica y propia, sólo brasileña, sólo del Brasil, sin deber nada a los libros, a las modas, a los hábitos importados de Europa: lo que yo quería", continúa Eca, " (y lo que constituiría una fuerza útil en el universo) era un Brasil natural, espontáneo, genuino, un Brasil nacional, brasileño, y no ese Brasil, que vi, hecho con viejos pedazos de Europa, llevados por el buque, y arreglados a la rápida, como paños de feria, entre una naturaleza inconsecuente, que les hace resaltar más el moho y las manchas".

Aunque el personaje ficticio -Fradique Mendes- declare al comienzo de su carta a Eduardo Prado, que reposaba en una "cuna refugio de árboles y fuentes", de los "sombríos esplendores de la Amazonía, y de la fatiga de las aguas atlánticas", Eca de Queiroz, sin haber estado nunca en el Brasil, sentía de lejos el artificialismo social: "recorrí todo el Brasil", dice Fradique Mendes, "en busca de lo nuevo y sólo encontré lo viejo, lo que ya es viejo hace cien años en nuestra Europa, -nuestras viejas ideas, nuestros viejos hábitos, nuestras viejas fórmulas y todo más viejo, gastado al máximo, como enteramente acabado por el viaje y por el solé

Eca de Queiroz reclamaba contra el constante falseamiento del espíritu brasileñop todo "torcido, contrariado en su manifestación original". "Era enda "politica, por las doctrinas de Europa, en Literatura, por las escuelas de Europa, en la sociedad, por las modas de Europa". En el campo intelectual, pro. sigue, "el Brasil es aún una colonia - una colonia del Boulevard-, letras, ciencias, costumbres, instituciones, nada de esto es nacional, todo viene del exterior, en cajones, por el barco de Bordéus, de modo que ese mundo, que orgullosamente se llama nuevo, el Nuevo Mundo, es en realidad un mundo viejísimo, y plegado de arrugas, de esas arrugas enfermizas, que nos dieron, a nosotros, veinte siglos de Literatura".

Las críticas de Eca de Queiroz tenían en parte procedencia, no obstante ciertas exageraciones naturales de un espíritu inquieto, irreverente, malicioso - pero con mucho sabor y mu* cha agudeza - por otro lado, era a veces llevado a cometer fallas de apreciación y análisis, porque se encontraba muy lejos del escanario de los acontecimientos, que nunca había tenido la oportunidad de ver con sus propios ojos.

El Brasil, realmente, vivía de cultura importada, lo que era natural en un país cuya colonización reflejaba la acción direc- 
ta de Europa, que la presencia portuguesa legó al país las instituciones sociales que le son pecualiares. En el proceso evolutivo de la sociedad brasileña durante el Imperio, y aun durante los primeros veinte años de República, se verificó, como el propio Eca de Queiroz hace reseña, "una teoría doctoral de, moralmente y materialmente, vestir al Brasil a la usanza europea, de francesismo, con remiendos de vago inglesismo y de vago germanismo". Y hasta de portuguesismo, detalle que Eca, tal vez intencionalmente, olvidó de incluir.

Entretanto, en la época de la crítica social de Eca de Queiroz, el año de 1888 la Literatura brasileña ya había dado señales de un comienzo, tímido, tal vez, pero positivo, de reacción contra aquello que más tarde se llamó colonialismo intelectual en relación a las formas ortodoxamente europeas. Basta citar el nombre del novelista José de Alencar, hoy reinterpretado en su auténtica fisonomía espiritual, revelándose un autor "empe. ñado en ser en lo posible brasileño, y no colonialmente portugués o subeuropeo" como el Profesor Gilberto Freyre, en notable trabajo de interpretación sociológica de la obra literaria de Alencar, vio el esfuerzo bien sucedido de la novela genuinamente brasileña.

Más adelante aún que José de Alencar, el Profesor Gilberto Freyre se revela comgiun tropicalista "que para afirmarse tropical, no precisó de repudiar sistemáticamente la herencia lusitana del Brasil, sino lo que esa herencia le pareció significar de imposición a los brasileños, por los èscritores portugueses más académicos, de una condición colonial o subportuguesa por él juzgada intolerable del punto de vista de la exigencia literaria o del lenguaje".

José de Alencar, siendo un romántico, en la forma y en la estética, fue, sin embargo, un lejano precursor de los modernistas de 1922, por las intenciones de crear un espíritu brasileño, una temática brasileña, un lenguaje brasileño. Lo que los modernistas propondrían en 1922, Alencar instintivamente esbozó a partir de 1857 , fecha de la aparición de su novela "O Guarani", además de haber sido, como acentúa Gilberto Freyre, un crítico social, un reformador de costumbres: se esfuerza "en el sentido de resolver lo brasileño, las complicaciones acumuladas en torno de los individuos por un sistema de familia considerado por algunos antinatural en sus excesos, reintegrándose a lo natural".

Ahora bien, José de Alencar, mucho antes de la crítica de 
Eca de Queiroz, ya se reveló, aunque en moldes de un pensa. miento romántico, lírico, idealista, contra todo aquello denunciado por la pluma espirituosa de Eca de Queiroz.

Muchos años, sí, habrían de transcurrir hasta el día del florecimiento del árbol del pensamiento brasileño - un florecimiento que llenó de colores, las más generosas, las más fuertes, las más arraigadas en el suelo, en un germinar de frutos incontenidos, en que se constituyó el movimiento modernista, a partir de 1922 a nuestros días.

La crítica de Eca, continuó hasta cierto punto válida por todo el período caracterizado por el encuentro de los siglos XIX y XX, y aún, durante los primeros años del siglo actual. $\mathrm{La}$ influencia europea en la literatura, en las artes, en las costumbres, principalmente de Francia, se sobrepuso a preocupaciones mayores de estudio, de análisis, de interpretación de las cosas brasileñas. Se procuraba ver al país y a sus instituciones a través de ideas y puntos de vista nutridos en obras de importación.

Es claro que aparecen algunastvoces aisladas, pero de gran expresión. En la crítica literaryia, por ejemplo, se destacan Araripe Junior, Silvio Romero, José Veríssimo, que ya indicaban una tomada de rumbo brasileño a través de sus ideas e interpretaciones con bastante fondfolisocial y telúrico. Otro nombre este con un ímpetu cósmico aún no revelado en ningún escritor hasta su tiempo, a crear una obra notable, plena de realidad brasileña, de mensaje social, de sugerencias para estudios más profundos sobre la tierra y el hombre brasileños, fue Euclides da Cunha, un pre-modernista que se sitúa más cerca de los modernistas que varias figuras ligadas, por el tiempo, con el movimiento de 1922. El crítico Antonio Cándido, en uno de los instantes felices de su "Literatura y Sociedad", habla de la obra maestra de Euclides da Cunha "Os Sertoes" como un marco, ella señala "un fin y un comienzo: el fin del imperialismo literario, el comienzo de análisis científico aplicado a los aspectos más importantes de la sociedad brasileña".

Tuvimos pensadores como Alberto Torres, historiadores, renovadores, como Joao Ribeiro, que introdujeron el elemento social en el estudio del pasado histórico brasileño: Oliveira $\mathrm{Li}$ ma, Vicente Licinio Cardoso; cuentistas de talento para reproducir tipus y costumbres del Brasil, como Monteiro Lobato; novelistas como Lima Barreto y Machado de Assis; ensayistas como Gilberto Amado, que brindaban una contribución nueva 
para las letras y el espíritu nacionales. Y, aún en la Historia, -e Historia renovada en métodos de investigación, análisis e interpretación- la gran figura de Capistrano de Abreu.

El movimiento modernista brasileño que se acostumbra iniciarlo, en el tiempo, por la Exposición de Arte Moderno realizada en Sao Paulo, durante la semana del 11 al 18 de febrero de 1922,es consecuencia de un largo proceso histórico y social resultante de las transformaciones operadas en la vida del país, y no un fenómeno puramente estético. Aquellas constantes culturales que Eca de Queiroz reclamaba en 1888, resumidas en la expresión: "el día dichoso en que el Brasil, por un esfuerzo heroico se decidió a ser brasileño a ser del Nuevo Mundo", sólo pudieron ser cumplidas integralmente cuando ciertas condiciones sociales coexistieron en el medio brasileño, factores capaces de desencadenar un moviminto que expresase el espíritu nuevo de la sociedad. El Brasil adelantó, materialmente, valiéndose de las técnicas y de los beneficios de la civilización moderna, y su transformación cultural fue un natural corolario.

En la primera década del sigla actual el Brasil era un país que contaba con menos de dieciocho millones de personas. La capacidad adquisitiva del pueblo, reducida por la modesta ren. ta de la mayoria de la población, no animaba ningún impulso de industrialización. El país importaba casi todo lo que con. sumía en productos máhufácturadostas La sociedad, esencial. mente agraria, semifeudal, y yaun patriarcal, cultivaba, es claro, el espíritu tradicionalista. La vida económica del Brasil tenía por base el comercio interno de mercaderías y la exportación de productos primarios, entre ellos, los más fuertes, los que sustentaban verdaderamente la conomía nacional: el café y el caucho. Las comunicaciones entre los varios puertos del país eran deficientes. Algunas líneas de ferrocarril se encargaban de unir los puntos de mayor importancia demográfica en el Sur y Nordeste. Las carreteras eran aún meros caminos pioneros. La espina dorsal de los transportes residía en la navegación marítima, sirviendo, en la extensa costa atlántica, los intereses económicos y sociales de los Estados de la Federación, desde el Amazonas hasta Río Grande do Sul.

Pero, este aspecto del Brasil, tradicionalista comienza a dar señales de modificación, a partir de la Primera Guerra Mundial. El país, desde el principio del siglo recibía un apreciable contingente de inmigrantes extranjeros. Se fundaron colonias de alemanes e italianos de Sao Paulo hacia el Sur. Portugueses, españoles y japoneses, sirios, libaneses, completaron 
el cuadro inmigratorio. En 1920, la población brasileña ya era de 30 millones de habitantes. En los Estados de Río de Janeiro, Minas Gerais, Sao Paulo, Paraná, Santa Catarina y Río Grande do Sul, es que se manifiesta, con más fuerza, la transformación social y económica.

En consecuencia, las capitales de esas unidades comienzan a centralizar, en detrimento del área rural, las energías creadoras de la Nación, surgiendo el fenómeno del urbanismo, cuya amplitud se torna, hoy en uno de los más serios problemas del país, con el estímulo, también, de la industrialización que se inicia después de la Primera Guerra, para tomar decisivo im. pulso después del segundo conflicto mundial.

Los primeros síntomas del movimiento modernista llegaron de Sao Paulo, el Estado más progresista, a través de las actividades de Oswald de Andrade, desde 1912, escribiendo ver'sos, sin métrica y sin rima, para escándalo de los tradicionalistas. Oswald regresó de Europa, donde tuvo noticia del Manifiesto Futurista de Marinetti, pero lo que realmente él soñaba realizar, junto con otros intelectuales convertidos al nuevo credo, era la renovación de los pruncipios estéticos, la ampliación de los procesos artísticos, Ja inspiración autóctona, la alineación del Brasil en las nuevas corrientes estéticas abiertas por el progreso del mundo y el comienzo de lo que sería su rápida marcha hacia el desarrollo esociadoye Ecconómico.

Lazar Segall, en 1914, y Anita Malfatti, en 1917, hacen las primeras exposiciones de pintura no académica. Esta última, influencia por la moderna escuela alemana, logró un éxito para la época, estremeciendo el dolce far niente de los académicos, y por eso fue bastante criticada como producto de la "paranoya o de la mixtificación": pero defendida por las figuras principales del naciente modernismo. Mario de Andrade, uno de los más combativos e influyentes modernistas, decía que la exposición de Anita Malfatti había conseguido "la regimentación, la consciencia de rebeldía de espíritu nuevo".

Treinta años después de aquella crítica de Eca de Queiroz, se cumplía su vaticinio: el verdadero, el libre genio de la Nación, antes constantemente falseado, torcido, contrariado en su manifestación original", comenzaba a florecer en la inteligencia brasileña por intermedio de un proceso cultural que tuvo como válvula de escape la semana de Arte Moderno, organizada por Oswald de Andrade, Di Cavalcanti, Mario de Andrade, Guilherme de Almeida, Agenor Barbosa, Ribeiro Couto, George 
Przirembel, Cándido Mota Filho y Joao Fernando de Almeida Prado.

El Brasil tuvo grandes cambios. La exportación del café y del caucho, a principios de siglo, proporcionaba recursos suficientes para la construcción de ferrocarriles, de puertos, de diques, de edificios. Las ferrovías llegaban al interior del país. Río de Janeiro y Sao Paulo ganaban una nueva fisonomía urbana, mientras una nueva clase, la de los obreros, surgía en las grandes ciudades, llegando, en 1917, a desencadenar una huelga con 70 mil adeptos en la ciudad de Sas Paulo. El Partido Comunista disemina las ideas de Marx y Lenin, abriendo un frente de reivindicaciones populares. La aristocracia rural pierde substancia para el capitalismo urbano-industrial.

La Semana de Arte Moderno vino a conštituir el estuario de las nuevas aspiraciones, fruto de la evolución social y económica del Brasil y del mundo. Paulo Prado, una de las expresiones del movimiento, da su definición: "La Semana de Arte viene a revelar al desierto de nuestro mundo lunar que una modalidad de pensamiento apareció con un gran Renacimiento Moderno. Con ella surge, entre nosotros, el sentimiento de inquietud e independencia que es la característica de un nuevo aspecto del espíritu humano. El mundo ya está cansado de las fórmulas del pasado; en todas partes y en todos los terre. nos - en la estética deslaśs cadles, tenrel anuncio, en los réclames, en los periódicos ilustradosi, cenelos grabados, en el mobiliario, en la novela - con una alegría inococlasta y juvenil se quiebran los antiguos moldes y desaparecen las viejas reglas, pesadas como cadenas (...). La Semana de Arte Moderno fue la primera protesta colectiva que se levantó en el Brasil contra esos fantoches del pasado. Así inició el grupo de Arte Moderno la obra de saneamiento intelectual de que tanto necesitábamos".

Al fin, el modernismo de 1922 rompió los compromisos del Brasil con un cierto colonialismo intelectual del que aún padecíamos, a pesar de la reacción de figuras aisladas, principalmente en las letras.

La inteligencia brasileña conquista su plena madurez, su completa autonomía, sin apartarse de las fuentes de nutrición universal. "El movimiento modernista", explica otro represen. tante suyo, el escritor Peregrino Junior, "promovió la orienta. ción de nuestro arte y de nuestra literatura en un sentido nítidamente nacionalista, de base humana y social, cuyas raíces 
se profundizan en' las fuentes del pueblo, en el corazón de la nacionalidad, en las tradiciones más puras de nuestra tierra y de nuestra gente".

El espíritu moderno, la voluntad de innovación, el interés por la tierra y gente del Brasil no se circunscribieron a un solo movimiento que se habría centralizado en Sao Paulo o en Río, los dos grandes centros de la vida social y económica, de mayor florecimiento intelectual. Este alcanzaría otras áreas del país a través de dos movimientos propios: Pernambuco y Río Grande do Sul, donde las tradiciones de regionalismo eran más vivas y, por eso mismo, sensibles a la revalorización, bajo el influjo de la estética moderna, de los elementos regionales.

En Río Grande do Sul, donde Joao Simoes Neto, desde 1912, había creado un tipo mejor de regionalismo, aparece la generación de los modernos: Vargas Neto, Darci Azambuja, Ciro Martins, entre otros.. El paisaje de los campos, el pastoreo, la influencia española de frontera, son las constantes del regionalismo gaucho.

Es en Recife, sin embargo, que surge el más fuerte y mejor caracterizado regionalismo, debido a la presencia de un joven pernambucano, estudiante de Sociología y Antropología en las Universidades de los Estados Unidos $y_{S}$ de Inglaterra, que regresaba a la patria despues de cinco años de ausencia. Gilberto Freyre -este es su nombre-inspira y dirige el Congreso Regionalista de Recife, realizado en Febrero de 1926. En esta ocasión, se da lectura al Manifiesto Regionalista por su autor Gilberto Freyre, que lanza los principios fundamentales del movimiento: rehabilitación de valores y tradiciones del Nordeste. Por lo tanto, modernismo y tradicionalismo juntos son una combinación de regionalismo y universalismo.

Hoy, la crítica más ilustrada del Brasil admite igual importancia a los modernismos de Sao Paulo y de Recife. Además de esto, los dos movimientos, aunque independientes uno del otro, van a desembocar en el mismo estuario cultural: la búsqueda de una fisonomía propia para la literatura brasileña, la valorización de la tierra y del hombre brasileño. En el movimiento de Recife, sus animadores llegaron a ser ridiculizados por vivir hablando de cosas hasta entonces despreciadas: las golosinas, los dulces, las chacras, los árboles, las huertas, los jardines, los juguetes para las criaturas, los azulejos de las casas, los muebles, las artes populares, la escultura, el teatro, el "ballet", la pintura mural. 
Las ideas defendidas por Gilberto Freyre repercutieron en la poesía de un Jorge de Lima, de un Ascenso Ferreira, en la novela de un José Américo de Almeida, de un José Lins do Rego, en la pintura de un Manoel Bandeira, de un Cícero Días, de un Luiz Jardim. Y creó una verdadera escuela de investigadores sociales y de brillantes ensayistas. El propio inspirador del movimiento, Gilberto Freyre, se tornó el mayor estudioso e intérprete de la sociedad patriarcal brasileña, bajo el ángulo histórico-social, sociológico, antropológico y psico-social. Es un nombre que atravesó las fronteras de su país, colocándose al lado de los grandes escritores y científicos sociales del mundo.

Los sucesos modernistas y regionalistas de Sao Paulo y de Recife prepararon, de cierto modo, un clima propicio para el desencadenamiento de la Revolución Militar de 1930, cuando termina el primer ciclo de la República proclamada en 1899 y se inicia una nueva etapa en la vida del Brasil. Es claro que determinadas causas económicas y políticas fueron las responsables directas de la aparición de este movimiento. Pero no se puede olvidar las fermentaciones de ideas renovadoras, de ideal político, de cambio de nútodos, de inconformismo. contra los tabús y los postułados establecidos, que animaron a muchos de los llamados revolicionarios.

El Profesor Tales débeded bajo del antropólogo "Chârlés 'wagley", de la Universidad de Columbia, intitulado "La Revolución Brasileña", interpretó fielmente las raíces del cambio operado en 1930: El movimiento de las fuerzas militares y de la opinión pública, victoriosas el 24 de Octubre se hacía en nombre de una crítica severa a instituciones y costumbres que caracterizaron la Primera República: el dominio de las oligarquías, la política de los gobernadores, el poder de los "coroneles", las elecciones fraudulentas, la crisis económica y el desorden financiero crónico.

En verdad la crisis era bastante más amplia, como indicaban los movimientos verificados en los dominios de las ideas, de las letras, de las artes. La tensión hizo romper el dique del sector político, y la extensión de esa ruptura, que, además, no se puede fechar alrededor de 1930, sino de todo el período que viene por lo menos del 22 , a través de episodios y fases de intensidad e incidencia diferentes, resultó, al final, un proceso de cambios del cual hoy se beneficia toda la vida nacional.

Nos parece justa, así, la observación de José Aderaldo Castelo sobre la importancia e influencia de los dos movimientos, 
el de Sao Paulo y el de Recife, para una nueva configuración de la vida brasileña: Estos dos movimientos quedarán, probablemente, como los más importantes en la revolución de las letras y de la vida en el Brasil en el sentido no sólo de autenticidad, como de la espontaneidad en la creación intelectual o cultural y de la auto confianza entre los brasileños. En el sentido de la liberación intelectual y artística del Brasil, de los excesos de subordinación colonial a Europa o a los Estados Unidos.

Pero es preciso no olvidar que algunas corrientes del Mo. dernismo tendieron, a partir de 1924, como señala Wilson Martins, a la literatura política. Al principio, acentúa el mismo autor, hacía cualquier tipo de totalitarismo, ya que existía en la consciencia de la época descrédito en el regimen de gobierno democrático. Se estaba, finalmente, en un mundo que asistía a las primeras experiencias del fascismo italiano y del comunis. mo ruso. El régimen de Mussolini era saludado como anti-liberal, anti-democrático. El personaje de una novela, aparecida en 1927, proclamaba que "la salvación estaba en la reacción fascista", porque el "fascismo eliminó las viejas ideas del sufragio universal y las abstracciones metafísicas de los ideólogos del 89". Y si el otro personaje contradecía estas ideas, observando que "el bolchevismo y el fascismo son la negación total de todos los valores democrátícos", el primero replicaba: "Sí, sólo que, como escribió Gerorge Valois Lenin es dictador de la barbarie mientras que Mussalinilesodictador de la civilización". Y distribuía elogios a los dictadores: Mussolini, Lenin, Primo de Rivera, Mustafá Kemal, reafirmando que "Europa rechazó la democracia".

Este diálogo un tanto ingenuo y forzado para obra de ficción, tiene, sin embargo, valor de posición de una época, teniendo en cuenta que se trataba de una conversación entre in. telectuales preocupados por el desarrollo de los acontecimientos políticos.

La división Derecha e Izquierda verificada entre los modernistas, también constituídos en varias corrientes - dinamistas, primitivistas, antropofagistas, nacionalistas, espiritualistas, exaltados - trajo al movimiento una fermentación de ideas y sugerencias que hizo al modernismo desaparecer como grupo, permaneciendo, no obstante, su caracterización fuerte de toda una época de la vida brasileña. Esta, finalmente, es la opinión del crítico Wilson Martins, cuyas palabras son bastante ilustrativas: "más que una simple escuela literaria, o aun un período de la vida intelectual el Modernismo fue, a mi entender, toda 
una época de la vida brasileña, inscrita en un largo proceso social e histórico".

Después de 1930 - el país vivía una nueva experiencia político-administrativa resultante de la revolución militar y popular de octubre -el modernismo había "cumplido su ciclo histórico", según la opinión de uno de los más autorizados estudiosos y críticos del movimiento, el escritor Mario de Silva Brito. Pero, perduran, muy fuertes, sus influencias en la vida intelectual y política del Brasil. La experiencia, las contradicciones, los ideales, de los primeros modernistas, se iticorporan a otros factores nuevos que hoy configuran la inteligeencia brasileña.

Lucio Miguel Pereira, escribió una síntesis de lo que representa el modernismo de 1922. El artículo está publicado en la revista "Cultura" de diciembre de 1922, y tiene el título de "Tendencia y Repercusión del Modernismo". Este pequeño trecho es uno de los balances más correctos hasta ahora escritos: "Como revolución, actuó sobre el medio, modificándolo; como revolución superó la fase destryactiva, orientándose hacia la constructiva. Contrariando el nombre, bajo lo moderno buscó lo permanente. Su espíritu, justamente por ser libre, por lo tanto elástico, no se detuvo en el-libertinaje, antes se canalizó hacia la búsqueda de patrones culturales más de acuerdo con nuestra manera de ser. Oriundo de corrientes ss téticas extranjeras, luego se nacionalizó; negador en su impetu inicial, rápidamente se tornó afirmativo; dogmático en sus fórmulas inaugurales no tardó en adquirir la maleabilidad indispensable para la acción; ávido de novedades en su origen, se acercó a una tradición más vivida de nuestro pasado literario; intelectualmente aristócrata en su instalación, rápidamente se humanizó; festivo y algo humorista en sus principios, ganó después la gravedad de los $1 \mathrm{~m}$ pulsos creadores; pareciendo, al principio, separatista, fue finalmente un fuerte agente de cohesión."

Se constituyeron, así, el modernismo y el regionalismo, en un solo agente catalizador de las energías espirituales del Brasil. No importa que se procure encontrar filigranas para diferenciaciones o independencia entre los movimientos de Sao Paulo y Recife. Ambos poseían el mismo sentido de renovación, de procura de un estilo, de una definición nítidamente brasileña. Ambos se completan por los objetivos comunes, aunque difieran en método o filosofía. Uno fue necesario al otro, y todos, finalmente, se beneficiaron con el espíritu creador de cada cual.

Una evaluación de los frutos producidos por los Regiona. 
lismos de Refice pueḍe expresarse a través de una obra que él directamente inspiró: "Casa Grande \& Senzala", que es considerada como un marco en nuestra historia cultural, porque renovó, revolucionó los estudios sociales e históricos clel país, abriendo perspectivas nuevas para la comprensión ¿ interpre. tación de la sociedad patriarcal brasileña. El libro, hoy consagrado en el mundo entero, es una epopeya literaria, porque Gilberto Freyre no se revela solamente como el científico social, aplicando, por primera vez en el país, un método de investigación, sondeo y evaluación de valores, sino, igualmente, el escritor de recursos artísticos, y hasta de osadías literarias.

Antes de "Casa Grande \& Senzala", que apareció en 1933, surgieron otras obras importantes, definiendo en colores de mucho frescor el modernismo naciente, aparecen con ímpetu de renovación: "Paulicéa Desvairada", en 1922, y "La esclava que no es Isaura", en 1925, de Mario Andrade, la personalidad literaria más multiforme del movimiento;"Retrato del Brasil", en 1928, un ensayo de Paulo Prado singularmente pesimista y no conforme por lo tanto, con la actitud positiva de los modernistas, entre los cuales Paulo Pardo se incluía, "Macunaina", en 1928, la novela de Mario de Andrade; "Martin Cerere" en 1928, poema de Casiano Ricardō: "Cobra Norato" en 1931, poema antropofagista de Raúl Bopp, calcado en las leyendas y en el paisaje de la Amazoníaiblicteca de Letras

Los nombres que representan el modernismo en su primera fase, y su continuación, a través del tiempo, forman una lista bastante larga. Entre ellos, sobresalen, en una visión más amplia:

Graca Aranha, con una novela pre-modernista "Canaá" publicada en 1902, y "La estética de la Vida", en 1920, y la novela "Viaje maravilloso", en 1930. Graca Aranha se integró al movimiento modernista a partir de 1924. Jorge de Lima, del grupo Nordeste, con su poesía regional; Manoel Bandeira, actualmente uno de los grandes de la poesía brasileña, agresó del simbolismo hacia el modernismo, considerado, además, como el poeta por excelencia nacional, el único que el modernismo produjo; Menotti del Picchia, del ala nacionalista del modernismo; Ronald de Carvalho, un poeta a lo Walt Whitman, desaparecido prematuramente en un accidente de automóvil; Oliveira Viana, cultor de la sociología histórica, y de altos méritos literarios; Mario de Andrade, un talento multiforme e inquieto, gran animador de las ideas modernistas; Oswald de Andrade, 
en la novela, es la figura de mayor combatividad del movimiento de 1922; Plinio Salgado, creador y Jefe del Integralismo, doctrina inspirada en el fascismo italiano, hombre de letras completo que produjo los mejores cuentos políticos de la primera fase del modernismo, en violenta contraposición con la ideología comunista; Alcántara Machado, muerto prematuramente, que se distinguió en el cuento y por la tendencia de crear nuevos rumbos literarios; José Américo de Almeida, autor importante en el campo de la novela regional y de la reforma social, abriendo una nueva fase de la historia literaria del Brasil con "A Bagaceira"; el poeta Augusto Frederico Shemidt; Carlos Drumond de Andrade, el poeta de fortísima personalidad, que viere ejerciendo influencia mayor en el panorama actual de la literatura brasileña, situándose entre los grandes poetas americanos; José Lins do Régo, nordestino, influenciado por las ideas regionalistas de Gilberto Freyre, es considerado el representante máximo de la novela del Nordeste; Jorge Amado, gran novelista de Bahía, al principio atraído por la ideología de Marx, y en su fase actual, de plena madurez de espíritu, escribiendo sus mejores obras como "Gabriela, Gravo e canela", "Os velhos marinheiros", "Dona Flor e seus dois-maridos", ya liberado, en la literatura, de los malos hábitos políticos a favor de un pura construcción artística, sin olvidar el fondo social; Gilberto Freyre, de quien ya hablamos a propósito de su papel de primer plano en las letras y en las ciencias sociales, configurando el pensamiento más avanzado en Ia Sociologia, en la Antropologia y en la Historia Social; Graciliano Ramos, un escritor sobrio y perfecto, novelista introspectivo y regional de un Nordeste diferente al Nordeste de José Lins do Rego y de Jorge Amado; Érico Veríssimo, tal vez el novelista más popular del Brasil, al lado de Jorge Amado, y una voz del extremo sur, al principio en la novela urbana y de costumbres, para después tornarse el autor épico de la trilogía de "O tempo e o vento" que procura reconstituir los orígenes y formación social de Río Grande do Sul; Joao Guimaraes Rosa, en el cuento y en la novela se inicia, por la forma peculiarísima de su estilo, una nueva fase en la literatura brasileña; Vinicius de Morais, poeta de gran fuerza lírica; Lucio Cardoso, novelista introspectivo; Raquel de Queiroz, con posición destacada en la novela nordeste; Rodrigo Mello Franco de Andrade, buen narrador del modernismo "mineiro", crítico de artes plásticas; Augusto Meyer, poeta y excelente ensayista del modernismo; Guilherme de Almeida, poeta, integrante del movimiento modernista; Ribeiro Couto, poeta, uno de los principales elementos del modernismo paulista y carioca; Murillo Mendes y su poesía lírica; Cyro dos Anjos, lírico e introspectivo 
produjo novelas de universo ficticio bastante rico; Cecilia Meirelles, cuya poesía llega a las raíces del simbolismo, tornándose, así menos modernista, pero no por eso menos brasileña; Otávio de Farias y Marqués Rebelo, ambos en la novela; Dalcidio Jurandir, dedicado a la ficción en paisajes y costumbres de su tierra natal, Pará. Sergio Buarque de Holanda, en la Historia Social; Alfonso Arinos de Melo Franco, en el ensayo; Otavio Tarquino de Souza, en la historia; Lucia Miguel Pereira, Alceu de Amoroso Lima, Silvio Julio, Agripino Greco, Sérgio Milliet, Temistocles Linhares, Waldemar Cavalcante, Olivio Montenegro, en el ensayo y en la crítica literaria; Arthur Cézar Ferreira Reis, en la Historia; Francisco de Assis Barbosa en el ensayo Literario; Josué Montelo, ensayista y novelista, dueño de un estilo personal y fluyente; Fernando Azevedo, humanista y pedagogo, autor de una Historia de Cultura brasileña, Luiz Viana Filho, maestro de biografía. Pedro Calmon, orador e historiador, Dinah Silveira de Queiroz, novelista. Celso Furtado, experto en la historia y análisis económico brasileño. Josué de Castro escribe agudos ensayos de Geografía Social.

Estos nombres se integran en-dos grandes corrientes principales del movimiento mođernista, dentro de las cuales subsisten varias sub-corrientes, según la clasificación propuesta por el crítico Afranio Coutinho; la corriente nacional y regional; la corriente subjetivista e introspectiva En la primera, se distingue el documentario urbano-social de ficción realista. Es la vida urbana de la clase media captada por la observación de un Lucio Cardoso, de un Armando Fontes, de un Oswald de Andrade, de un Alcantara Machado, de un Ribeiro Couto, de una Rosalinda Coelho Lisboa, de un Jorge Amado. Es el neo-realismo, que también aparece en la novela documental regionalista, creando los ciclos: de la caña de azúcar, del cacao, con un José Américo de Almeida, un Jorge Amado, un José Lins do Rego, una Raquel de Queiroz, un Nestor Duarte, a los cuales se unen los narradores y novelistas del ciclo estanciero gaucho, con Darci Azambuja, Ivan Pedro Martins, Ciro Martins, y los del ciclo del caucho o del ciclo amazónico: un Ferreira de Castro, que, aunque portugués, escribió " $\mathrm{La}$ Selva", con su propio género de vida, la más grande novela del ciclo; un Carlos de Vasconcelos, un Peregrino Junior, un Lauro Palhano.

La segunda corriente, o sea la subjetivista e introspectiva, quiere la indagación interior, desea la discusión de los problemas del alma, del destino humano, el análisis de las reacciones entre el hombre y hombre. Es la situación literaria de un Lúcio 
Cardoso, de un José Geraldo Vieira, de un Cornélio Pena, de un Otávio Faria, de un Ciro dos Anjos, de un Aníbal Machado.

Debe también destacarse el incremento de los estudios históricos y sociales después de la eclosión del modernismo. En ese campo, las figuras regionales de Gilberto Freyre, en el Nordeste, y Arthur Ferreira Reis, en la Amazonía, son estrellas de primera magnitud, y con gran valor aparece la contribución de Moisés Velhinho, Dante Laitano, Manoel Diegues Junior, Sérgio Buarque de Holanda, Djacir Menezes, Luiz de Cámara Cascudo, Américo Jacobina Lacombe, José Honório Rodríguez.

La influencia del movimiento modernista no sólo se hizo sentir en la estética literaria, en la filosofía de interpretación y revalorización de cosas brasileñas. También se manifestó en la creación de una lengua brasileña, apartándose de los procesos de la Filosofía portuguesa. Los modernistas procuran transplantar a la lengua escrita las varias expresiones y peculiaridades del lenguaje popular, lo que, además, viene de encuentro a los propósitos del movimiento de resistir al énfasis de oratơria, al cultivo de los preciosismos al lenguaje "clasicizante y lusitanizante". En la poesía, alejáronse de las rimas clásicas, de los poetas perfectos y convencionales.

Aquello que ya se venía plasmando en las categorías populares, desde los tiempos deslat Coloniastos sea, la dulcificación del portugués por el contactoogonidadengtuasdel indio y del africano, -y que tanto incomodaba a los puristas lusitanos, aún a fines del siglo pasado-, los modernistas se propusieron consagrar definitivamente, incorporando valores populares en el lenguaje literario. Menotti del Picchia, en 1923, ya registrabada el hecho de que el Brasil "comenzaba a crear una lengua con elementos típicos autónomos, construcciones y modismos originales, que, tornados clásicos por el uso, constituirán las bases de la "Gramática Brasileña", que ya existen y que falta tan solo codificar.

Otro modernista, Oswald de Andrade, también justificaba por el año de 1924, en su manifiesto "Pau brasil", una verdadera revolución lingüística: "La lengua sin arcaismo, sin erudición. Natural y neológica. La contribución millonaria de todos los errores". En su propio reducto del clasicismo literario, que era, en aquel tiempo, la Academia Brasileña de Letras, viene de uno de sus miembros revelados, el escritor Graca Aranha, la protesta contra la orientación del cenáculo en conservar la pureza del idioma portugués, procurando ignorar las transformaciones operadas en el Brasil. En esa ocasión, Graca Aranha decía "no somos la cámara mortuória del Portugal". 
Es indispensable coger en la exposición de los modernistas históricos la impresión de profundidad y de vehemencia con que ellos se integran en la campaña de abrasilerar la lengua. Plinio Salgado, por ejemplo, habla del "grito de libertad contra todos los prejuicios literarios del pasado, contra el academismo artificial, contra la mecanización de los procesos de estilo, contra las cansadas filosofías occidentales". Grito de libertad dado en Sao Paulo, el año de 1922, en la Semana de Arte Moderno. Desde entonces, él concluye "comenzamos a leer un libro abierto de la vida nacional, las verdades humanas esenciales (...) A un concepto clásico, estático de idioma, opusimos la concepción clara y dinámica de la lengua brasileña, en función histórica de existencia y de transformación".

Así, términos y expresiones de la lengua hablada, coloquial, popular, se consagraron en las páginas de los poetas y prosadores modernistas para escándalo y reacción de muchos gramáticos y filólogos ortodoxos, lo que, exceptuando ciertas exageraciones, cierto mal gusto, ciertas excentricidades, resultó en un trabajo de fecundidad nacional, puesto que, como acontece en los modernistas sensibles al sentimiento estético, todo se hace sin perjuicio de la obra de arte. En este sentido, la esciitora modernista Raquel de Queiroz se manifestó contra la negligenciá de prestar el valor estrictamente literario de la literatura: "la única finalidad rea dod perfabajo Giterario, como de pintura y de música, es inducir una obra de arte. Todas las otras consideraciones y consecuencias son secundarias". Y esto, justamente esto, es lo que procura hacer el pensamiento brasileño cle vanguardia: alcanzar una forma de expresión donde la belleza artística coexista con el sentimiento y las aspiraciones del país. Las conquistas del modernismo, expurgados sus excesos, sus desvíos, sus distorsiones, ya se incorporaron definitivamente a la literatura brasileña $\mathrm{y}$, por lo tanto, al alma brasileña.

Sería interesante, ahora, examinar las repercusiones del modernismo de Sao Paulo en el extremo Norte, donde, singularmente, no ocurre influencia del regionalismo tradicionalista del Nordeste, área ecológica más identificada con la Amazonía, pues es preciso tener en cuenta la intensa comunicación sentimental entre las dos regiones, en virtud de la presencia de un iuerte contingente demográfico nordestino en el país del caucho. Muchas de las personalidades actuantes en la vida pública de Belém y. Manaus, en la redacción de los periódicos, en los grupos literarios, provenían de los estados nordestinos, que ofrecieron no solo los inmigrantes para los "seringais", sino también, las inteligencias inquietas, deseosas de expandir sus energías en el 
mundo verde que les prometía posición social, fortuna, un lugar al sol.

El regionalismo tradicionalista de Recife, modernista a su modo, consiguió regimentar un gran número de escritores y artistas jóvenes que habían dado las primeras señales de inquietud espiritual, y el deseo de abrir nuevos caminos, en la "Revista do Norte", aparecida en Recife, en 1923. Después, la fundación deI Centro Regionalista en 1926, sin olvidar la aparición del "Livro do Nordeste, comemorativo centenário do Diário de Pernambu. $\mathrm{co}^{\prime \prime}$-iniciativas de Gilberto. Freyre-, todos estos hechos fundamentaron el movimiento de renovación nordestina, cuya influencia se hizo sentir en otras capitales del Nordeste: Maceió, Paraiba, Natal y Fortaleza. Entre tanto, no alcanzaron con la misma fuerza e importancia el Extremo Norte, que escogió el modernismo del eje Sao Paulo-Río como fuente de inspiración.

Para esto, contribuyeron algunos hechos aislados que vale la pena recordar, como, por ejemplo el contacto personal, o a través de correspondencia, de hombres de letras de la Amazonía con intelectuales del movimiento de Sao Paulo. Es el caso de Raúl Bopp, autor de uno de los trás bellos poemas brasileños, inspirado en las leyendas y costumbres amazónicas: "Cobra Norato". Bopp pasó algún tiempo en Belem do Pará y Manus, llegando a cursar durante un año la Facultad de Derecho en la capital parense. Esta conviyenctac con efirmedio, con la gente die la tierra, se manifestó en su obra literaria de poeta modernista, y en ciertos episodios que marcaron la participación de elementos regionales en las actividades del modernismo. Otro nombre, el del escritor también modernista Peregrino Junior, cuya experiencia amazónica está patente en gran parte de su bibliografía, sirvió de puente espiritual entre las ideas renovadoras de Sao Paulo y el Extremo Norte.

Belem y Manaus, después del conflicto mundial de 1914. 1918, pasaron por una transformación social impuesta por el fenómeno de la guerra y la desvalorización económica del caucho, producto que les proporcionara un notable desarrollo urbano, más ligado, en sus ángulos materiales y espirituales, a Europa que propiamente a Río de Janeiro. La guerra interrumpió esa corriente de ideas, de sentimientos, y hasta de umportación de utilidades que todos ya se habían habituado a disfrutar en la vida diaria. La inteligencia del extremo norte, paulatinamente, comienza a descubrir valores en el sur del país. Los movimientos del sur, de rebeldía armada que se realizaron en los año de 1922 y 1924, la marcha de la "Columna Prestes" por la 
intrincada selva brasileña, repercutieron en la región amazónica, originando una consciencia de alerta sobre problemas brasileños por ser resueltos. El modernismo del eje Sao Paulo-Río encuentra, así, un campo propicio para extenderse en la amazonía. En Belem los intelectuales se reunen en torno de Andrade Queiroz, figura muy bien informada sobre los acontecimientos de Sao Paulo. En el periódico "Folha do Norte" su director Paulo Maranhao abre las puertas para la colaboración de los nuevos. Bruno de Menezes escribe el primer poema modernista en el Pará. En la capital de Amazonas surge el núcleo más activo del espíritu moderno, bajo el liderato de una prensa de categoría, tanto en el aspecto intelectual y gráfico.

Cuando se realicen estudios para revelación y análisis del movimiento modernista en la Amazonía, Manaus indiscutiblemente, ocupará lugar de mayor relieve. Fue en la capital amazonense donde se editó la primera revista dentro del espíritu moderno "Redención". También en Manaus aparecieron publicaciones innovadoras, como "Primeiro de Janeiro", "Equador" y "Selva". A pesar de que estos periódicos recibían colaboración de autores clásicos, la ided-fuerza que los distinguía era lo moderno y lo brasileño, la voluntad de crear literatura y arte brasileñamente $\mathrm{y}$, también, regionalmente.

Intelectuales de Mahohas mañtienen asidua correspondencia con Mario de Andrades, Oswaild lidenAndrade, Pascoal Carlos Magno, Jorge Amado. Raúl Bopp escribe a amigos amazonenses y los "estimula a dar más atención al indio, a consultar la floresta, a "ahorcar a los retrógrados con cipó", a no tener vergiienza del caimán y del boi-bumbá, a demoler 'la "vieja sensibilidad de bachiller, del literato hueco y palabrero" a tomar, en fin, "el pulso de la tierra" expulsando "los preciosismos franceses", el "salón azul y otras quinquillerías cretinas". Por otro lado, la revista "Equador" muestra que es preciso "trabajar en la preparación de la consciencia nacional, curvarse en el ejercicio de las fuerzas expresivas de la raza, investigándolas, interpretándolas". Denuncia la "etiqueta pasada de moda", que "dañó el arte brasileño con extranjerismos retóricos". Por eso la necesidad de creer en el nacimiento de una "hora de sol animadora de una consciencia nueva", de un ritmo brasileño, de preocuparse por la mentalidad social y física absolutamente brasileña, y "mirar de frente a las realidades semi-bárbarbas del medio amazónico".

Mario de Andrade se interesó vivamente por el folklore y por la naturaleza de la amazonía, en búsqueda de algo específicamente brasileño, que se puede encontrar en su novela rapsodia 
"Macunaina", en el cual son valorizados tipos y leyendas del Amazonas con la original ficción del escritor paulista. Más tar de, cuando Mario de Andrade visita la Amazonía, entrando en contacto con intelectuales amazonenses y paraenses, se inspira en una localidad del río Javarí para dar título a su libro de poemas "Remate de Males".

Todo esto hizo aproximar a los intelectuales amazónicos el modernismo de Sao Paulo-Río, encontrándose, aún, en el movimiento antropofagista, que también nació en la capital bandeirante, un punto común de aproximación entre paulistas y amazónicos. Los excesivos matices folklóricos del movimiento sólo podían despertar el entusiasmo de los intelectuales amazónicos, guardianes de una tradición muy rica y llena de originalidad. Como bien expresó Abgar Bastos, el nuevo sentimiento brasileño-amazónico en la literatura "ya no se sentía avergonzado de andar a pie por el suelo, tras del mato, indio, macumba, tajá, ninhocao, uirapuru".

Así, Manaus se convirtió, en el Extremo Norte, en centro más dinámico de la difusión del credo modernista, y no es de admirar que la ciudad, después de 1930, pudiera ofrecer, en el campo de los estudios sociales e históricos, dos nombres de proyección: Araujo Lima y Arthur Cezar Ferreira Reis, con los pies bien puestos en la tierrajobectará, en da línea ufanista, presentase a Raimundo Morais gepun escritoro original que también tuvo mucha experiencia amazonense- $y$, posteriormente, al novelista parense Dalcidio Jurandir que se reveló con vigor telúrico, siendo incluído en el pos-modernismo, que en la novela y en el ensayo recibió influencia cultural del nordeste.

El movimiento modernista de 1922, también creó un espíritu nuevo, una filosofía propia, en las Artes Plásticas y en la $\mathrm{Ar}$ quitectura. Los avances verificados en ese campo son tan importantes como en la Literatura. Es sólo observar la fase anterior al año de 1922 y ver las constantes del academicismo internacional, de origen francés, imperar en las artes plásticas. La Escuela de Bellas Artes, en Río de Janeiro, sufría influencia directa de los métodos pedagógicos y estéticos de su congénere en París. Todo lo que se pensaba y hacía era dentro del eclecticismo europeo: neo-clasicismo, romanticismo, naturalismo. Ni la aparición de la pintura impresionista de Eliseu Visconti, un italiano que llegó muy niño al Brasil y allí formó su mentalidad, fue capaz de emocionar a los academistas brasileños. Visconti, como más tarde su discípulo, el amazonense Manoel Santiago, comenzó, por la primera vez, a revelar la naturaleza brasileña 
en formas y tonos diferentes al colorido sombrío y artificial de los pintores académicos.

Fue, sin embargo, la revolución modernistas de 1922, la que trajo consigo las concepciones renovadoras de las artes plásticas. Es preciso no olvidar que, propiamente, la revolución modernista comenzó en las artes plásticas: la pintora Anita Malfatti, paulista, hija de italiano, con su "fiesta de forma y fiesta de color", expone, en 1917, en la ciudad de Sao Paulo, 53 trabajos suyos. La propia artista los define: "Era la poesía plástica de la vida. Transponía el color del cielo, para poder descubrir el color diferente de la tierra. Transponía todo. ¡Qué alegría! Encontraba y descubría los planos con colores y formas nuevas, en las personas y paisajes".

Anita Malfatti se revela con un audaz avance en relación al tímido impresionismo iniciado por Eliseu Visconti. Su pintura es expresionista, y esta osadía le costó la reacción inmediata y cruel de los críticos y de los academistas. Casi al mismo tiempo, Víctor Brecheret se revela en el proyecto del Monumento a las Banderas, en 1922, construido más tarde, que hoy es una de las muestras históricas del modernismo brasileño. Oswaldo Goeldi, exponiendo en Río de Janeiro en 1921, sus xilo-grabados expresionistas, se consagra, al lãdo de Livio Abramo, como los mejores grabadores modempisdel Birasitras

\section{"Jorge Puccinelli Converson}

El influjo benéfico de la Semana de Arte Moderno, fue el responsable de la creación de un arte auténticamente brasileño. Cándido Portinari, ex-académcio se transforma en la figura dominante de las artes plásticas nacionales. Los temas brasileños, principalmente el Nordeste, sirven de inspiración a Portinari para pintar, en gestos dramáticos, aumentados por su fuerte expresionismo, las escenas del trabajo, la miseria humana, lo patético de la vida. Una pintura en que hay, también, mensaje social.

Pero, hay otro grupo de artistas modernos, como Alberto Guinard, José Pancetti, Alfredo Volpi y Djanira, que prefieren interpretar por la forma y por los colores vivos un Brasil más simple, más lírico. Los motivos de regocijo popular, los aspectos más tranquilos del paisaje. Tarsila do Amaral y Di Cavalcanti, figuras de relieve de la Semana de Arte Moderno, aprendieron valores del cubismo, transformándolos en una técnica expresionista brasileña o, mejor, aprovecharon elementos universales para expresar lo nacional. 
La escultura tiene sus grandes exponentes en Maria Martins, José Pedrosa, Bruno Giorgi, Celso Antonio, Alfredo Ceschiati Vera Dianacopolis, además del pre-modernista Vitor Bre. cheret, autor del ya referido Monumento a las Banderas, levan. tado en Plaza Pública de la ciudad de Sao Paulo. En el grabado, se destacan, la brasileña nacionalizada Fayga Ostrower, que obtuvo en 1958, el premio internacional de grabado de la Bienal de Venecia, Marcello Grassman, con su figurativismo agresivo, $y$, más recientemente, Dora Basilio y Rossini Pérez. Todos ellos crearon, con su arte personal, un universo brasileño de expresión.

La comprensión y aceptación de los trabajos de estos artistas está evidente en la presencia, sea en la pintura, grabado, escultura o en diferentes aspectos de la vida brasileña: lienzos, murales, azulejos de Portinari, pinturas de Djanira, Di Cavalcanti, decoran edificios públicos y transatlánticos nacionales. Portinari recibió el pedido del panel "Guerra y Paz" que forma parte del patrimonio del edificio de las Naciones Unidas, en Nueva York. Alfredo Ceschiatti es autor de la escultura, que día a día se va haciendo más famosa en el mundo entero, existente en el jardín del Palacio Alvorado, en lánovísima Brasilia. Bruno Giorgi hizo el monumento a la Juventud del Ministerio de Educación, en Río de Janeiro y eI monumento a los "Candangos", en la Plaza de los Tres Poderes, en Brasilia. María Martins fue la autora de aquel magnífico gallo que teasorna una de las paredes externas de la Maison de France, en Río de Janeiro.

La creación del Museo de Arte de Sao Paulo, en 1943, y de Jos Museos de Arte Moderno de Sao Paulo, en 1947, y de Río de Janeiro, en 1949, abrió nuevos y anchos horizontes para el desarrollo artístico del país.

Estas instituciones han revelado una función dinámica: no son apenas simples muestras de obras de artistas nacionales y extranjeros, sino también estimulantes de un trabajo de investigación, de la técnica de enseñanza y experimentación, tanto de las artes utilitarias como en las artes industriales. También, la aparición de las Bienales de Sao Paulo, desde 1951, proporcionó el florecimiento de un interés colectivo mayor para las artes a través de exposiciones retrospectivas del futurismo y del cubismo. Generalmente, más de sesenta países participan en las Bienales de Sao Paulo.

Por otro lado, aparecieron en Río y Sao Paulo, a partir de 1960, varias galerías de Arte, donde talentos nuevos tienen la 
oportunidad de revelación y valorización de su producto artístico. Y, paralelamente a todo esto, surgen los cultores del tachis. mo, cuyo mayor representante es Antonio Bandeira, de los figurativismos entre los cuales se encuentra Inimá de Paula, Ibere Camargo, Henrique Oswald, sin olvidar el abstraccionismo geométrico, lanzado por un grupo de jóvenes en la I Bienal de Sao Paulo y que hoy alcanza madurez en el arte de un Aloisio Carvao, de una Ligia Clark, de un Milton Cista. Finalmente, en esta rápida mirada al panorama del Arte en el Brasil, se puede juzgar todo lo que ya se alcanzó como forma de expresión brasileña, siempre con la tentativa de conseguir un equilibrio entre lo universal y lo nacional.

La Arquitectura brasileña también se ha colocado a la vanguardia del movimiento modernista, pues es considerada una de las más significativas del mundo. Antes de la Semana de Arte Moderno, o "Art Nouveau", de importación francesa, constituyó el estilo predilecto, que se hacía acompañar por un "ecletismo refinado" según Lucio Costa. En 1922, tuvieron lugar dos hechos importantes para el desarrollo de la Arquitectura en el Brasil: La Exposición del Primer Centenaria de la Independencia, realizada en Río de Janeiro, y la Semaná de Arte Moderno, en Sao Paulo. Para las conmemoraciones del Primer Centenario, se reunió un pequeño número de arquitectos que tuvo a su cargo la elaboración de los proyectos para la Exposición. En esa oportunidad, los arquitectos lanzaron una corriente de opinión que pretendía incorporar constantes culturales del arte colonial del Brasil, en la forma de un neo-colonialismo, que tuvo cierta boga. Pero, con las ideas revolucionarias de la Semana de Arte Moderno, lo que prevaleció fue la transformación completa en las concepciones de la Arquitectura, sobretodo después de la Revolución Militar de 1930.

De ahí en adelante, se plasma un nuevo Arte Arquitectónico, armonizado con el medio y las tendencias psico-sociales brasileñas. La primera gran generación de arquitectos está dirigida por Lucio Costa, el autor del plano de Brasilia. En el período gubernamental de Getulio Vargas, de 1930 a 1945, surgen arquitectos de mayor inteligencia y sensibilidad para atender a la "manera brasileña" de construir, sin omisión de los valores universales, como, por ejemplo la técnica y las concepciones de Le Corbusier, el gran arquitecto francés que ejerció bastante influencia en la formación del espíritu moderno de la Arquitectura brasileña.

Además, Le Corbusier puede ser considerado el ordenador 
de los principios de la Arquitectura Moderna en el Brasil. El edificio del Ministerio de Educación, en Río de Janeiro - primer sintoma de cambio en las reglas tradicionalistas, a favor de una concepción nueva-, fue proyectado por Le Corbusier, que llegó al Brasil por invitación del Ministro de Educación, Gustavo Capanema. Desde ese momento, la inquietud espiritual dominante en varios arquitectos brasileños, sedientos por renovar su arte encontró, en la técnica y en los procesos de Le Corbusier, los fundamentos esenciales para ordenar sus ímpetus de modernismo, que se tradujeron a partir de-esa época, en una escala creciente de proyectos y realizaciones.

El Ministro Gustavo Capanema fue una especie de papa administrativo del modernismo brasileño: encargado de la dirección de su gabinete estaba el poeta Carlos Drumond de Andrade. Rodeaban al Ministro, figuras de relieve de las ideas nuevas que sensibilizaron el espíritu de Gustavo Capanema. Esta es la razón por la cual, en esa fase, arquitectos modernos, como Oscar Niemeyer, encontraron campo propicio para efectivar sus avanzadas creaciones.

E1 Brasil Moderno presenta briflante equipo de arquitectos a cargo de la promoción de una verdadera revolución artística: además de Lucio Costa y Oscår Niemeyer, los hermanos Roberto (Marcelo, Milton y Maurícío) dRino Levi, Alfonso Reidy, Henrique Mindlin, Sergio BernalesıcTodos ellos, y tantos otros imbuídos de espíritu modernista, procuran variantes de identificación mayor con el paisaje brasileño. El uso de un lenguaje internacional es visiblemente suavizado, armonizado, por las peculiaridades del medio que les inspira la creación de valores $\mathrm{o}$, a veces, la recreación de valores ya empleados anteriormente, sobre todo en la arquitectura colonial dentro de un sentido funcional. La construcción de Brasilia, verdadero laboratorio de experimentación de formas plásticas y de concepciones osadas, obedeciendo el proyecto de Lucio Costa y Oscar Niemeyer, es una muestra del vigor creativo de la arquitectura brasileña, que se complementa con el arte de jardinería paisajista creada por Burle Marx, nombre mundialmente solicitado para dar el toque final a las estructuras proyectadas por los arquitectos. Es cuando entra el arreglo y la distribución de plantas y flores coloridas en los espacios determinados por una plástica ondulante y plena de sentido estético. Jardines tan bellos y tan útiles en un país tropical, donde la naturaleza exhuberante ofrece rica y variada flora, que el genio artístico de Burle Marx supo aprovechar y valorizar. 
Las ideas modernas también estimularon el arte musical y si hablamos de música moderna luego se destaca el nombre de Heitor de Villa-Lobos, cuya temática llega a las profundas raíces de la tierra. Substancialmente modernista, en busca de una nueva forma de expresión, y de fuentes brasileñas de inspiración, el arte de Villa-Lobos encontró en la naturaleza, en el folklore sugerencias para afirmarse en la búsqueda permanente de las constantes nacionales. Pero, al contrario de otros compositores de folklore, que conservan las estructuras principales clel material recolectado, Villa-Lobos da expansión a las energías latentes del folklore y crea su propio mundo de tonos y semitonos con vehemencia rítmica y lirismo cósmico. Sus poemas sinfónicos, las "Bachianas brasileñas" - "una curiosa unión del estilo de Bach y de la música folklórica"- sus fantasías y variaciones, sus orquestaciones, revelan una extraordinaria imaginación musical, hoy considerada una de las mayores en las dos américas.

La inteligencia brasileña ganó con el modernismo los componentes de fuerza, de renovación, de expresión, de tradición que hoy ofrecen dimensiones espirituales y sentimentales al país, dentro del más puro brasilerismo.

Biblioteca de Letras

«Jorge Puccinelli Converso" 